International Review of Research in Open and Distributed Learning Volume 22, Number 4

November - 2021

\title{
Exploring Open and Distance Learning Reform at the National University of Lesotho: A Managerial Perspective
}

Malefetsane Nketekete and Mamoeletsi Limakatso Mojalefa

Department Business and Management Development, National University of Lesotho

\begin{abstract}
This study investigated how open and distance learning (ODL) reform was managed within the Institute of Extramural Studies (IEMS), at the National University of Lesotho (NUL). The reform was introduced during the 2017/18 academic year with first-year programmes in three departments: (a) Adult Education; (b) Business and Management Development; and (c) Research, Evaluation, and Media. The study employed interviews and analysis of institutional documents as data collection techniques. Interviews were held with eight programme coordinators, four department heads, and the director of IEMS. Purposive sampling was used to select the participants to the study given their strategic position in the management and implementation of the reform. Qualitative content analysis was used to interpret the data. The findings suggested that the ODL programmes were introduced without a policy and comprehensive plan. The implementation faced several challenges such as finance, as well as infrastructural and human resources. Evidence from the literature has suggested that compared to face-to-face strategy, ODL as an educational strategy requires special resources, support, and funding. Thus, curricular materials should be adapted for the ODL context, taking into account students' characteristics. The study found that these pertinent requirements were not considered, and implementation continued as if the reform still constituted face-toface or campus-based instruction.
\end{abstract}

Keywords: implementation, learning, open and distance learning, open learning 


\section{Introduction}

Worldwide, open and distance learning (ODL) is becoming an established strategy in the field of education (Nyoni, 2014; United Nations Educational, Scientific and Cultural Organization [UNESCO], 2002). Like other institutions across the global, the National University of Lesotho (NUL) sees ODL as a viable strategy for "opening up opportunities to higher education and developing human resource" (NUL, n.d. p. 10). In its strategic plan of 2015-2020, the NUL sees the significance of ODL strategy for opening up access to the university, leading to higher enrolment in different educational programmes. Opening up access to its programmes would improve cost-effectiveness due to economies of scale.

As a concept, ODL connotes a spatial relationship between a learner and teacher (student and tutor) engaged in a learning enterprise, whereby the two are separated by geographical distance. Cant et al. (2013) defined ODL "as a learning situation where the student is geographically separated from the lecturer" (p. 5673). According to these authors, such an arrangement posed challenges to institutions of learning as they promoted the acquisition of knowledge and skills. These challenges may have originated from the fact that it is not only the physical or geographical space that exists between students and tutors, but psychological and communication gaps as well (Benson \& Samarawickrema, 2009; Limtrairut \& Marshall, 2020; Stein et al., 2005). ODL tutors have confronted the challenge of closing these gaps to enhance effective learning (Cant et al., 2013; Santally et al., 2012). The NUL sees ODL as opening access to students wherever they are. Adopting UNESCO's definition of ODL, NUL (n.d., p.6) put it as follows:

the terms open learning and distance education represent approaches that focus on opening access to education and training provision, freeing learners from the constraints of time and place, and offering flexible learning opportunities to individuals and groups of learners.

To effectively implement its ODL strategy, the university developed a policy on open and distance learning in dual mode, in order "to inform and support distance learning programmes at NUL" (NUL, n.d. p.14). Green (1994) acknowledged that there was "no single definition of policy to mirror the full range of ordinary usage" (p. 1). This has led experts in the field to adopt broad perspectives regarding the term policy in order to accommodate different ideas on the concept. Guba (1984) has suggested three different typologies, namely, policy-in-intention, policy-in-action, and policy-in-experience. Tyack and Cuban (1995) as cited by Looney (2001, p. 154) identified three different aspects of policy-"policy talk, policy action, and policy implementation". From the analysis, it appears that policy-in-intention and policy talk represent policy as documented, expressing official position of an institution. These aspects could be equated with what Brownson et al., (2009, p. 1578) referred to as "small p policies" which constitute organisational guidelines, internal agency decisions, or memoranda. Thus, the ODL policy at NUL constituted the organisational guidelines related to ODL strategy being introduced there. These were therefore, general statements that guided the organisation's decision making (Smit \& Cronje, 1997). Ball (1994; cited by Looney, 2001, p. 154) referred to these as policy text, in that policy is the management tool that guides decision making.

At NUL, the implementation of ODL policy was placed under the Institute of Extra Mural Studies (IEMS). IEMS is an integral part of NUL, founded in 1960 as the extension arm of the university responsible for "bringing the university to the people" (Tlelase, 1986, p. 1). In describing its role, in 1981 the then ViceChancellor described IEMS as a "catalystic agent which excites, educates, creates, develops, and moves on 
toward innovative ways of helping the people to help themselves” (Setsabi, 1983, p. i).

In the 2017/18 academic year, IEMS started transforming its programmes into ODL mode, starting with first-year courses. These programmes were Diploma in Management, Bachelor of Arts in Business and Entrepreneurship, Diploma in Mass Communication, Diploma in Adult Education, and Bachelor of Education in Adult Education.

This study explored how ODL reform processes have been managed at NUL. The exploration was aligned with the university's ODL policy and other course or programme development processes. This study was guided by a main research question:

- How have ODL reform processes been managed by the IEMS?

This main question was addressed by examining the following operational questions:

- What policies are in place for the implementation of ODL?

- Who are the key players in the implementation of the ODL programme?

- How do they collaborate in the process?

- What are their intended, perceived, and actual roles in the process?

- What guides decision making in the process?

\section{Literature Review}

\section{ODL as an Education Strategy}

The introduction of ODL fulfils a number of goals. These goals justify the popularity of ODL as a significant strategy in education provision compared to face to face-to-face conventional learning or campus pedagogy. The improvement of access has been identified as the main goal for adopting an ODL strategy (Aluko, 2011; Braimoh, 2003; Makhanya et al., 2013; Nage-Sibande et al., 2011; Yasmin, 2013). Yasmin (2013) observed that the potency of ODL in improving accessibility to education lies in its flexibility, as it provides an opportunity to people who could not attend school as the result of distance, life conditions, as well as financial and academic constraints. Melton (2002, p. 6) elaborated the issue of accessibility in that it "opens up education to students wherever they might be located and increases access to education by removing unnecessary barriers." Leeds (2013) described openness as a key factor of accessibility. Nyabanyaba (2013) further observed the potential of ODL in improving access to education by vulnerable and marginalised people such as people with special disabilities. Gilliet (2012) also argued that ODL opens up opportunities to education by special groups such as people with disabilities, refugees, and prison inmates.

Melton (2002) identified the second goal of ODL as its responsiveness to student's needs. Students are free to determine their own goals; responsiveness helps them recognise their potential, thus encouraging 
lifelong learning (Melton, 2002). UNESCO (2002) observed that, due to its flexibility, ODL provides students opportunities to combine their work and study, since students can always tailor their learning programme according to their needs. Thus, studying need not interfere with their work as may be the case with face-to-face conventional education.

The third goal of ODL is its flexibility in allowing the design of highly structured self-study materials, incorporating multimedia tools to facilitate learning (Melton, 2002). Online systems or learning platforms have been successfully employed in ODL to further enhance flexibility in delivering educational programmes. Conventional face-to-face tuition requires that students physically attend classes and lectures, while ODL institutions offering instruction through different platforms such as print materials, online, and e-learning platforms allow greater flexibility in terms of time and space (Romero \& Usart, 2014). While flexibility may be inherent in ODL tuition, self-regulation and time management techniques by students are crucial (Romero \& Usart, 2014). Melton (2002) further observed that effective learner support is enhanced when it accounts for learners' local contexts and conditions. Related to the accessibility factors, an ODL strategy is regarded as highly cost-effective, in terms of optimizing student numbers, due to decentralised student support systems (Melton, 2002). It has been noted that high-quality materials and systems are critically important for the success of ODL.

\section{The Need to Manage ODL Strategy}

Despite ODL's plausible goals, Yasmin (2013) contended that improved access to education was not automatic; ODL should be coupled with processes such as teaching, assignment completion, making use of student support services, and taking examinations. ODL has been regarded as an educational innovation intended to address the issues of access to education (Mukama, 2018). As such, it requires change management strategies to ensure that it achieves its goals. Such strategies should recognise the complexity of change and its multiple dimensions (Fullan, 1991; McRoy \& Gibbs, 2009). According to McRoy and Gibbs (2009) change required strong leadership able to

communicate the desired vision, model the roles that will lead to effective implementation, and possess the managerial skills to deal with aspects of change such as barriers and fear, as well as being endowed with the ability to recognize and engage with informal power agents who may resist the change process. (p. 687)

McRoy and Gibbs (2009) further acknowledged the difficulty of undertaking changes within university contexts, as such changes are normally undertaken under the pressure of budgets and unclear objectives. However, it has been observed that changes guided by policy frameworks have been effectively implemented (Ghavifekr et al., 2013; Mischke, 2010). According to Ghavifekr et al. (2013), the role of leaders in change management was easier when changes were vision- and policy-driven, as they enhanced organizational performance and promoted successful implementation of the change.

While the benefits of ODL are acknowledged worldwide, it is generally observed that institutions "are still failing to recognise particular key planning and implementing steps which could make the difference in successful and sustainable distance education initiatives" (Minnaar, 2013, p. 82). Minnaar's (2013) research, using template analysis, provided insight on successful implementation of ODL, which may be 
instructive to the Lesotho context. From the analysis of a database on ODL literature, Minnaar (2013) provided a framework that can assist in understanding the management and implementation process of ODL. The following are the key points in this framework.

- Strategy for ODL planning and implementation must be mandated by the government.

- A move towards ODL means redefining the institution as a whole; comprehensive planning is essential. Such planning involves a SWOT analysis, gap analysis, and functional analysis to establish the feasibility and criteria for planning. Different aspects need to be considered, including hardware, software, distance delivery technologies, technical staff, and academic support for staff (Knipe et al., 2002; Levy, 2003).

- Basic requirements include instructional development support staff, administrative support, student services, financial plans, costing, as well as staff development and training (Braimoh \& Lekoko, 2005, cited by Minnaar, 2013, p.89).

- Enabling policies should be in place to provide the framework for decision making and operations, and to enhance the quality of programmes. These policies include board, collaborations, course offerings, curricula, support, staff training, conflict management, profit sharing, as well as control of resources and certification (Braimoh \& Lekoko, 2005, cited by Minnaar, 2013, p.89).

- An ODL institution needs human resource policies on compensation, evaluation and course evaluation, promotion, performance management, and intellectual freedom.

- Different policies are required to address staff support, staff development/training, skills training, course/programme support, local facilities, and leave aspects (Gellman-Danley \& Fetzner, 1998; Simonson \& Bauck, 2003, cited by Minnaar, 2013, p.89).

- Legal policies should be included to guide staff on aspects such as intellectual property, plagiarism, liability, educational technology, and labour relations.

- ODL institutions need student policies to regulate aspects such as registration, resources, training and tutoring, assessment, and student support services. Technical policies, including ICT issues, Internet, and contractual agreements, are crucial for the smooth running of ODL. ODL also needs fiscal policies on some student issues as well as state funding and contracts.

\section{Methodology}

The study was exploratory, intended to gain insight into how ODL programmes were implemented or managed by IEMS. A number of reforms have been undertaken by the NUL but no studies have been undertaken to investigate the implementation processes of such reforms. This study provides an opportunity to gain insight on how reforms are managed by the NUL. Therefore, the current study was the first to address the management processes of ODL implementation by the university. 
Purposive sampling was used to select the participants to the study given their strategic position in managing and implementing the reform. Qualitative content analysis was used to interpret the data.

Purposive sampling was appropriate because of the limited number of primary data sources available to contribute to the study. Specifics of the purposive sample were linked to the nature of participants' strategic positions in implementing the ODL strategy. Face-to-face interviews were held with eight programme coordinators, four department heads, and the director of IEMS. Programme coordinators were directly involved in ODL implementation, while the Director of IEMS, as head of the institution, was responsible for leadership direction of the ODL policy and implementation process. The interviews were open, guided by the research questions. Each interview was recorded and later transcribed. Qualitative content analysis was used to interpret and analyse data.

In addition, institutional documents related to NUL's ODL policy were analysed using a content analysis technique and triangulated with interview data.

\section{Findings}

The operational research questions were used to organise and present the findings of the study.

\section{Policy Framework}

This section answers the operational research question: What policies are in place for the implementation of $O D L$ ? Data related to this question came from interviews and document analysis. It was observed that the ODL policy was developed mainly to guide the processes of implementing ODL. The policy, titled Policy for Open and Distance Learning in Dual Mode stated that it will "provide guidelines for the development of the ODL systems and structures based on the principles of flexibility, accessibility and studentcenteredness" (NUL, n.d., p. 14). The policy further stated that "its purpose is to guide decision and actions taken by administrators, academics, researchers, management, support and professional staff in providing services and support for ODL learners" (NUL n.d. p.15). However, interviewees indicated that they never consulted the ODL policy during implementation. For instance, one participant, a programme coordinator, stated that "I am not aware that the policy is in place and that we were expected to adhere to it." However, the director was aware that the policy was a guiding tool towards ODL implementation. It was further observed that the policy was approved after the processes of implementing ODL had started. Though couched in general terms, the policy indicated the basic processes to be followed in implementing ODL. A key section of the policy provided for the systems that had to be in place for effective ODL implementation, including (a) academic systems, (b) teaching and learning processes, (c) delivery channels, (d) information and communication technologies, (e) learner support systems, and (f) administrative systems. According to comments by participants in the study, the requirements prescribed by the policy were not adhered to for example, no special investment was made in information and communication technologies to support ODL. In addition, even though ODL requires more support to students to mediate transactional distance, there were no learning support systems in place.

Some of the critical success factors in ODL implementation including legal policies (Minnaar, 2013) and 
human resource policies (Gellman-Danley \& Fetzner, 1998; Simonson \& Bauck, 2003; as cited by Minnaar, 2013) were neither covered by the ODL policy nor considered during implementation. The policy did not specifically address human resource issues, legal issues, technical issues, and others. It emerged from interviews that the part-time staff appointed for ODL streams had reduced contact periods, and subsequently, their remunerations were reduced. Despite relentless complaints from staff members, this was not addressed, to the extent that each department used its own discretion. It further emerged that ODL students were still subjected to the same assessment policy as those studying face-to-face. For instance, students were required to repeat the whole year if they had not passed the minimum credit hours and, in some cases, some were discontinued from the programmes.

\section{Key Stakeholders in ODL}

To understand the management processes inherent in ODL implementation, it was important to identify and collect data about the key stakeholders. Data was collected from documents and interviews, and was guided by the operational question: Who are the key players in the implementation of the ODL programme? It has been observed that the policy for ODL was developed mainly to guide the processes of implementing ODL and identified the stakeholders to be involved in the implementation. These stakeholders were the University Council, Senate and executive management, Director of IEMS, Pro-ViceChancellor, Institute registrar, learners, programme coordinators, ODL coordinator, academic staff, online and face-to-face tutors, markers, material designer/developer, and counsellors.

Programme coordinators who were members of an ODL steering committee provided information on the role and membership of the committee. It emerged from the interviews that most interviewees were not familiar with the policy document. However, the director's responses reflected the content of the policy document. This might be the fact that the director requested to be given time to study the policy. It emerged from the interviews that the interviewees did not know the policy document.

\section{Collaboration Among Stakeholders}

Effective collaboration is very important for the successful implementation of an innovation. It was, therefore, important to establish whether there was any collaboration among stakeholders. Data collection was guided by the third operational research question: How do they (stakeholders) collaborate in the processes?

From the interviews, it emerged that IEMS established the ODL steering committee consisting of programme coordinators. For the first two years (2017/18 to 2018/19) the steering committee was chaired by the director of IEMS. Subsequently, an ODL coordinator was appointed at the start of the 2019/20 academic year.

Participants, with the exception of the director, did not respond beyond the operational activities of the ODL steering committee, and it was evident that they were not familiar with the ODL policy. Analysis of the ODL policy document revealed that it recognised the importance of collaboration among various stakeholders. Further, the policy identified overall institutional roles and also roles at different managerial levels, in addition to specific structures. The role of the NUL as an institution was well-articulated in the ODL policy, as was the role of IEMS as an institution within NUL. The ODL policy made IEMS the custodian 
of ODL initiatives at NUL, tasked with overall management, coordination, and support of ODL implementation.

Key personnel identified by the ODL policy included the distance learning coordinator as well as online and face-to-face tutors. The ODL policy clearly articulated the roles of these personnel. It also identified different operational levels important to successful policy implementation. First, the policy identified institutional accountability which rested with the NUL. Second, it identified faculty-level accountability which related to different faculties of the university. Third, it identified departmental-level accountability which pointed to the programmes and courses offered through ODL. Fourth, it identified academic-level accountability which related to the design and development of materials, as well as the appointments of the relevant staff and their development. Fifth, it identified administrative-level accountability which was mainly concerned with support to both academics and learners by administrative staff members. Lastly, it addressed learner-level accountability which mainly outlined the roles and responsibilities of learners within the ODL system. Thus, the policy outlined the roles and responsibilities of each structure, which indicated how collaboration may be achieved.

\section{Roles of Stakeholders}

In order to examine different stakeholders' roles, it was necessary to establish whether stakeholders understood their intended and actual roles. Perceived roles indicated how stakeholders translated their intended roles, as established by the policymakers. Actual roles are the enactment of the perceived and represent the actual implementation. The level of implementation was thus indicated by gaps or congruency among intended, perceived, and actual roles. Data collection was guided by the operational research question: What are their intended, perceived, and actual roles in the processes?

The policy outlined the intended roles of the university as an institution, IEMS as a part of the university, the faculties, the departments, specific officers (e.g., director), tutors and coordinators, and learners. The perceived roles of all stakeholders were determined from the interview data; however, only the ODL steering committee roles were referred to. Respondents did not identify the perceived roles of other stakeholders. From the interviews, the actual roles of the steering committee were identified as timetable preparation for ODL contacts classes and coordinating different departments. Since the interviewees were not conversant with the ODL policy, it was particularly challenging to establish gaps or congruence among different roles. This was further complicated by the fact that there was no comprehensive plan to implement ODL. From the interviews, it became clear that the ODL implementation process was not supported by any budget.

\section{The Basis for Decision Making}

Knowledge of what factors informed decision making in the process of ODL implementation indicates whether the implementation went according to the plan or policy as intended. Data on the bases for decision making was solicited through the final operational research question: What guides decision making in the processes?

From analysis of the policy document, it was clear that the policy itself was to be a guiding tool for decision making processes on ODL implementation. For instance, the policy stated that it will "provide guidelines for the development of the ODL systems and structures based on the principles of flexibility, accessibility 
and student-centeredness" (NUL n.d., p. 14). The policy further stated that its purpose was to guide decision and actions taken by administrators, academics, researchers, management, support and professional staff in providing services and support for ODL learners (NUL n.d., p. 15).

However, from the interviews, the ODL policy as the basis for decision making was only mentioned by the director. It was understandable given that he had been given an opportunity to study the policy before responding to the questions. The director mentioned the importance of NUL's Senate and management, NUL statutes and ordinances, and dialogue in the decision-making process. Generally, the interviewees showed a little understanding of the importance of policy in guiding implementation.

\section{Conclusions and Recommendations}

This study's main research question was: How have ODL reform processes been managed by IEMS? This required an understanding of management processes.

Participants rarely referred to the existing policy, which was supposed to be used as the basis of planning implementation of ODL. It would appear that the level of engagement was at the low level of management, namely the ODL steering committee, while top and middle management were not visible. From an organisational perspective, the situation of loose coupling manifested itself.

One would argue that the policy document might not have served any purpose other than reflecting the visionary position of the university towards adopting the worldwide recognised strategy of ODL. The policy itself provided the basic or essential elements necessary for the effective implementation of ODL strategy. Significantly, key strategies emerging from the literature do not appear to have been considered in the process of implementation as well as in policy formulation. This may be indicative of a lack of effective management of the reform and may eventually lead to the unsuccessful implementation of the project.

Based on our findings, it may be strategically significant to re-energise collaboration from all levels of university leadership through an action-oriented plan. In particular, such a plan should address all the shortcoming which have been observed. This requires four key actions.

First, the university administration, specifically the principal officers such as the Vice-Chancellor, the ProVice-Chancellor, deans of faculties, and other senior personnel within the university administration must be engaged. This should be done to ensure maximum cooperation among the authorities. Second, all necessary enabling policies such as staffing and human resources, budgeting, ICT and e-learning policy, marketing and other pertinent policies need to be put in place. Third, since effective implementation is content-specific, it is important to understand the unique characteristics and constraints of open and distance education within the Lesotho context. Finally, stakeholders, specifically the ODL coordinator and other programme coordinators, should familiarise themselves with the ODL policy. 


\section{References}

Aluko, R. (2011). Inclusion and exclusion in higher education: Paradoxes in distance education.

Progressio, 33(2), 121-135.

https://repository.up.ac.za/bitstream/handle/2263/18687/Aluko Inclusion(2011).pdf?sequence

$\equiv 1$

Benson, R., \& Samarawickrema, G. (2009). Addressing the context of e-learning: Using transactional distance theory to inform design. Distance Education, 3o(1), 5-21. https://doi.org/,DOI: $\underline{10.1080 / 01587910902845972}$

Braimoh, D. (2003). Transforming tertiary institutions for mass higher education through distance and open learning approaches in Africa: A telescopic view. SAJHE/SATHO, 17(3), 13-25. https://journals.co.za/doi/pdf/10.10520/EJC37029

Brownson, R. C., F. Chriqui, J. F., \& Stamatakis, K. A. (2009). Understanding evidence-based public health policy. American Journal of Public Health, 99(9), 1576-1583.

https://ajph.aphapublications.org/doi/pdfplus/10.2105/AJPH.2008.156224

Cant, M. C., Wiid, J. A., \& Machado, R. (2013). The characteristics of a good ODL practitioner. Gender \& Behaviour, 11(2), 5673-5687. https://hdl.handle.net/10520/EJC144836

Fullan, M. (1991). The meaning of educational change. Cassell.

Ghavifekr, S., Afshari, M., Siraj, S., \& Razak, A. (2013). Vision-Driven strategies and policies for managing educational systemic change: A qualitative analysis. Australian Journal of Basic and Applied Sciences, 74), 333-341. http://eprints.um.edu.my/9791/1/00005891 93367.pdf

Gilliet, C. (2012). The role of ODL in the advancing access to education for special needs groups. Huria: Journal of the Open University of Tanzania, 13(2), 401-409. https://www.ajol.info/index.php/huria/article/view/110868

Green, F. T. (1994). Policy questions: A conceptual study. Education Policy Analysis Archives, 2(7), 1-14.

Guba, E. G. (1984). The effect of definitions of policy on the nature and outcomes of policy analysis. Educational Leadership, 42(2), 63-70.

Leeds, B. (2013). Assessing the potential of OERs for ODL. SAJHE, 26(6), 1490-1507. https://journals.co.za/doi/pdf/10.10520/EJC153339

Limtrairut, P., \& Marshall, S. (2020). A New Design Guideline for Mobile Learning Application: Transactional Distance Perspective. 2020 IEEE 9th Global Conference on Consumer Electronics (GCCE), 610-614. doi: 10.1109/GCCE50665.2020.9291976

Looney, A. (2001). Curriculum as policy: Some implications of contemporary policy studies for the analysis of curriculum policy, with particular reference to post-primary curriculum policy in the 
Republic of Ireland. Curriculum Journal, 12(2), 149-162.

http://dx.doi.org/10.1080/09585170121749.

Makhanya, M., Mays, T., \& Ryan, P. (2013). Beyond access: Tailoring ODL provision to advance social justice and development. SAJHE, 27(6), 1384-1400.

https://journals.co.za/doi/pdf/10.10520/EJC153346

McRoy, I. \& Gibbs, P. (2009). Leading Change in Higher Education. Educational Management Administration \& Leadership, 37(5) 687-704. doi: $10.1177 / 1741143209339655$

Melton, R. F. (2002). Planning and developing open and distance learning: A quality assurance approach. Routledge Falmer.

Minnaar, A. (2013). Challenges for successful planning of open and distance learning (ODL): A template analysis. International Review of Research in Open and Distributed Learning, 14(3), 82-108. https://doi.org/10.19173/irrodl.v14i3.1387

Mischke, G. (2010). Towards effective curriculum design in open distance learning. Progressio, 32(2), $145^{-163 .}$ https://www.saide.org.za/resources/Conf\%202010/Mischke\%20G\%20Towards\%20effective\%20 curriculum\%20design $\% 20 . .$. pdf

Mukama, E. (2018). From policies to implementation of open distance learning in Rwanda: A genealogical and governmentality analysis. Journal of Learning for Development, 5(1), 40-56. http://oasis.col.org/bitstream/handle/11599/2555/PDF?sequence $=4$

Nage-Sibande, B., van Vollenhoven, W. J., \& Hendrikz, J. (2011). ODL and access to higher education: The experiences of the University of Botswana. Progressio, 33(1), 138-154. https://repository.up.ac.za/bitstream/handle/2263/18875/NageSibande Access\%282011\%29.pd $\underline{\mathrm{f} \text { ?sequence }=1}$

National University of of Lesotho (n.d). The National University of Lesotho Strategic Plan 2015 - 2020: On Its platinum Jubilee. National University of Lesotho.

Nyabanyaba, T. (2013). Growth of ODFL in Lesotho: Increasing educational access for members of marginalised communities. SAJHE 27(6), 1401-1413. https://journals.co.za/doi/pdf/10.10520/EJC153345

Nyoni, J. (2014). E-readiness of open and distance learning (ODL) facilitators: Implications for effective mediation. Perspectives in Education, 32(3), 78-91. https://hdl.handle.net/10520/EJC160060

Romero, M., \& Usart, M. (2014). The temporal perspective in higher education learners: Comparisons between online and onsite learning. European Journal of Open, Distance and e-Learning, 17(1), 190-209. https://files.eric.ed.gov/fulltext/EJ1033728.pdf 
Santally, M. I., Rajabalee, Y., \& Cooshna-Naik, D. (2012). Learning design implementation for distance elearning: Blended rapid e-learning techniques with activity-based pedagogies to design and implement a socio-constructivist environment. European Journal of Open, Distance \& ELearning, II. https://www.researchgate.net/publication/257947596

Setšabi, A.M. (1983). Forward. IEMS Annual Report for the Year 1981/82. The National University of Lesotho.

Smit, P. J., \& Cronje, G. J. (1997). Management principles: A contemporary edition for Africa. Juta.

Stein, D. S., Wanstreet, C. E., Calvin, J., Overtoom, C., \& Wheaton, J. E. (2005) Bridging the transactional distance gap in online learning environments. The American Journal of Distance Education, 19(2), 105-118. https://doi.org/, DOI: 10.1207/s15389286ajde1902 4

Tlelase, B.A. (1986). Preface. IEMS Annual Report for the Year 1984/85. The National University of Lesotho.

United Nations Educational, Scientific and Cultural Organization. (2002). Open and distance learning: Trends, policy and strategy considerations. UNESCO.

https://www.saide.org.za/resources/Library/Moore\%20-\%20UNESCO\%20ODL\%20trends\%20p olicy\%20and\%20strategy\%20.pdf

Yasmin. (2013). Application of the classification tree model in predicting learner dropout behaviour in open and distance learning. Distance Education, 34(2), 218-231.

http://dx.doi.org/10.1080/01587919.2013.793642

\section{Athabasca \\ University}

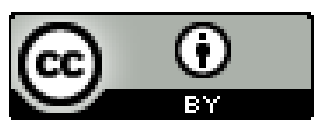

